\title{
A RELIGIÃO EM FEUERBACH: DEUS NÃO É DEUS, MAS O HOMEM E/OU A NATUREZA DIVINIZADOS
}

\author{
Eduardo F. Chagas ${ }^{1}$
}

\begin{abstract}
Resumo: Em sua obra principal, A Essência do Cristianismo, Feuerbach mostra que o Cristianismo coloca no seu cume um deus pessoal, ilimitado, que cria através do "puro pensar" e do "querer" a natureza e o homem. Já em A Essência da Religião e nos Complementos e Esclarecimentos para a Essência da Religião, Feuerbach analisa a religião natural, na qual deus é um ser físico, idêntico à natureza. Assim como a religião cristã transformou a essência humana em deus, do mesmo modo a religião natural fez da natureza um deus. Mas, para Feuerbach, o deus cristão não é um ser não-humano, mas o próprio homem adorado como divino, assim também o deus físico da religião natural não é deus, mas a própria natureza divinizada. Frente a tais religiões, Feuerbach quer resgatar tanto o homem como a natureza e estabelecer entre eles uma nova relação: o homem não apenas como um ser espiritual, mas também de necessidade, finito, sensível, que depende da natureza, e esta última não como obra de deus, nem do homem, mas como instância originária, como causa dela mesma, e que sem ela, o homem é nada, não pode ser. Homem e natureza se completam: o homem deve sua existência, seu nascimento e preservação à natureza, mas esta é melhor preservada, desenvolvida e conhecida por meio do homem.
\end{abstract}

Palavras-chave: A Crítica da Religião em Feuerbach; Homem, Natureza e Deus em Feuerbach; A Determinação Humano-Natural de Deus em Feuerbach.

Abstract: In his main work, The Essence of Christianity, Feuerbach shows that Christianity posts to its summit a personal limitless God who creates by means of "pure thinking" and "will" nature and man. On the other hand, in The Essence of Religion in Complements and Clarifications for the Essence of Religion, Feuerbach analyses natural religion in which God is a physical being not different from nature. In the same fashion that religion changed human essence in God, likewise natural religion changed nature into God. But, according to Feuerbach, the Christian God is not a non-human being, but man himself adored as divine, likewise the physical God of natural religion is not God but nature itself in a divine configuration. Faced by those religions, Feuerbach aims at rescuing not only man but also nature and establish between them a new relationship: man not only as a spiritual being but also created out of necessity who is finite, sensible, dependent on nature, while nature is not as a work of God, neither of man, but a original instance, having itself as cause, and man owes his existence, its birth and preservation to nature, but it is by means of man that nature is better preserved, developed and known.

\footnotetext{
${ }^{1}$ Doutor em Filosofia pela Uni-Kassel - Alemanha. Professor da Graduação e da Pós-Graduação do Curso de Filosofia da Universidade Federal do Ceará (UFC) e Colaborador do Programa de PósGraduação da Faculdade de Educação (FACED) da UFC. Pesquisador Bolsista do CNPq. Editor da Revista Dialectus (http://www.revistadialectus.ufc.br/index.php). E-mail: ef.chagas@uol.com.br. Homepage: http://efchagasufc.wordpress.com. Vitae (Lates): http://lattes.cnpq.br/2479899457642563 .
} 
Keywords: Critique of Religion in Feuerbach, Man, Nature in God and Feuerbach, Human and Natural Determination of God in Feuerbach.

\section{A Antropomorfização de Deus na Religião Cristã}

Com deus (Gott) está associado um nome que o homem usa para expressar ou a sua própria essência ou a essência da natureza. Partindo, inicialmente, da tese, que veremos a seguir, a saber, que deus e o homem são, no Cristianismo, idênticos, Feuerbach revela que o segredo (Rätsel) recôndito da teologia cristã é nada mais do que a antropologia (Anthropologie) ou, melhor dizendo, que o conteúdo do ser infinito (in abstrato) (deus) é o ser finito (in concreto) (o homem). No Cristianismo, o homem (Mensch) se concentra apenas em si mesmo e faz de si uma essência absoluta e sobrenatural, ou seja, um deus.

Assim, deus é a essência declarada, anunciada, do sujeito como objeto absoluto. Em oposição a Hegel, que afirma, em sua filosofia da religião, que o saber do homem acerca de deus é o saber de deus acerca de si mesmo, postula Feuerbach, para transformar a teologia em antropologia, o princípio oposto que reza: o conhecimento do homem de deus é o saber do homem de si mesmo; não foi deus que criou o homem, mas o homem quem criou deus a sua imagem e semelhança. ${ }^{2}$ Apoiando-se em Homero, escreve Feuerbach, os

deuses são seres que só existem para e através dos homens; por isso não velam o homem quando este dorme, mas quando os homens dormem, dormem também os deuses, isto é, com a consciência do homem se esvai também a existência dos deuses. (FEUERBACH, 1967, p. 99.)

Conquanto Feuerbach conclua disso que a consciência do homem de deus é a sua autoconsciência, chama ele mesmo atenção para o fato de que o homem religioso não é a si imediatamente consciente de que sua consciência de Deus é a própria consciência de sua essência, porque a ausência dessa consciência fundamenta de facto a essência da religião cristã. Destarte, ele designa a religião em geral apenas como

\footnotetext{
${ }^{2}$ No artigo Zur Beurteilung der Schrift "Das Wesen des Christentums" (1842), Feuerbach elucida da seguinte maneira a diferença entre a filosofia de Hegel e a sua: "Minha filosofia da religião é tão pouco uma explikation da hegeliana, [...] que ela deve ser concebida e julgada, pelo contrário, apenas como opposition. O que, a saber, tem em Hegel o significado do secundário, do subjetivo, do formal, isso tem para mim o significado do primitivo, do objetivo, do essencial. Segundo Hegel, o sentimento, o afeto, o coração é, por exemplo, a forma, na qual se deve submergir o conteúdo derivado da religião, com isto ela torna-se propriedade do homem; para mim, o objeto, o conteúdo do sentimento religioso é nada mais do que a essência do sentimento." (FEUERBACH, 1970, p. 229-230).
}

\begin{tabular}{|l|l|l|l|l|}
\hline Qevista Dialectus & Ano 2 & n. 4 & Janeiro-Junho 2014 & p. 78-91 \\
\hline
\end{tabular}


contemplação (Anschauung) “infantil”, "fantástica” da essência humana, ou seja, como a primeira e indireta autoconsciência do homem. Na religion, o homem não vê, porém, em si mesmo sua essência (a humanidade, o gênero), mas fora de si mesmo, pois sua própria essência é a ele objeto como uma outra essência. Melhor dizendo: ele realiza nela sua essência, embora ele não reconheça o objeto como produto de sua atividade. A intention de Feuerbach, particularmente frente a religião, que considera seu objeto como sobrehumano, consiste em provar que a oposição entre o divino (sagrado) e o humano (profano) é ilusória (illusorisch), porquanto o conteúdo da religião (cristã) é inteiramente humano. Todas as declarações sobre deus são para ele apenas afirmações sobre o homem, pois na medida em que deus é aquilo o que o homem é, a saber, uma essência sensível, viva, afetuosa, podem ambos (deus e o homem) serem reconhecidos, portanto, apenas partindo desta essência.

A acepção antropológica de deus, isto é, a reduktion da teologia (Theologie) em antropologia (Anthropologie) ou da essência universal de deus na essência natural do homem é o ponto central em torno do qual gira a obra principal de Feuerbach, $A$ Essência do Cristianismo (Das Wesen des Christentums). Para Feuerbach, o deus cristão significa nada mais do que o proceder do homem frente a si mesmo, considerado como um ser diverso dele, existente para si, livre, então, de sua corporeidade (Leiblichkeit) e finitude (Endlichkeit). Todas as qualidades "da essência divina são", como Feuerbach acentua, “determinações humanas" (FEUERBACH, 1973, p. 49); deus e o homem são um, pois deus não é um ser sem determinação, despojado das qualidades humanas, porque a negation de tais determinações significaria igualmente a incognoscibilidade, a irreconhecibilidade e indeterminidade de deus.

\footnotetext{
Um ser sem qualidade é um ser sem objetividade, e um ser sem objetividade é um ser nulo. Por isso, quando o homem retira de deus todas as qualidades, é este deus para ele apenas um ser negativo, nulo. Para o homem realmente religioso não é deus um ser sem atributos, porque é para ele um ser certo, real. (Idem).
}

Pois o ser, que realmente é, tem uma existência qualitativa, determinada e, por isso, finita. Esta position de Feuerbach é uma refutação (Widerlegung) direta à concepção de deus como uma existência universal, transcendente, isto é, como uma existência sem qualidade, que é, todavia,

o fogo, o oxigênio, o sal da existência. Uma existência em geral, uma existência sem qualidade, é uma existência insípida, uma existência sem gosto. [...] Somente quando o homem perde $o$ sabor da religião, quando a própria religião se torna insípida, só então torna-se também a existência de deus uma existência insípida." (Ibidem, p. 51).

\begin{tabular}{|l|l|l|l|l|}
\hline Qevista Dialectus & Ano 2 & n. 4 & Janeiro-Junho 2014 & p. 78-91 \\
\hline
\end{tabular}


Por conseguinte, deus não é nenhum ser em si, isto é, nenhuma existência autônoma, uma vez que ele é possível só através de determinadas qualidades, que são determinações finitas, particularmente humanas. Se o homem existe, precisamente, apenas como um ser determinado e corresponde ao critério ou à medida da existência de deus, este é, de certo modo, para ser concebido como uma "existência determinada", então como uma essência humana ou, pelo menos, como semelhante ao homem; ele está qualitativamente determinado no homem, assim ele não tem nenhuma outra representação a não ser humana. "Mas deus não é”, como Rawidowicz observa, "o homem empírico, ele é, ao contrário, 'o próprio sentimento do homem livre de todas as repugnâncias." (RAWIDOWICZ, 1964, p. 95). Partindo dessa ponderação, a saber, que os predicados atribuídos a deus, como onipotência, onisciência, onipresença, justiça, amor, bondade, são conceitos do gênero humano, puramente antropomorfismos, Feuerbach quer superar não só a discórdia, ou seja, a oposição entre deus e o homem, mas também a causa desta cisão entre ambos, isto é, a teologia mesma.

Deus não é originariamente nenhum nome próprio, nenhum ser em si e por si, mas essencialmente uma qualidade determinada por um outro ser; nenhum sujeito, mas predicado, nada mais do que uma expressão do sentimento e da fantasia humana; isto é, não é o ser de deus enquanto tal, mas a determinidade do mesmo sua verdadeira essência. Se a "existência de deus", para poder ser, precisa de predicados, ela tem, separada deles, tão-somente uma existência abstrata, isto é, ela não possui nenhuma certeza (Gewissenheit) imediata, absoluta ou objetiva. A negation dos predicados é simultaneamente a negação de deus, pois aquilo que constitui uma existência (ou um sujeito), isso se encontra apenas no predicado. Isso é mui evidente na teologia cristã, na qual os predicados manifestam a verdade e a realidade do sujeito. A propósito, Feuerbach destaca a diferença entre os significados do sujeito e do objeto e nega a autonomia (Selbständigkeit) dos predicados divinos, pois para ele tais predicados são simplesmente qualidades humanas, adoradas, no entanto, como essências sublimes, universais e absolutas. "Deus é o conceito da majestade, a mais alta distinção; o sentimento religioso é o mais alto sentimento de conveniência.” (FEUERBACH, 1973, p. 58). Mas não por meio de uma natureza puramente divina, isto é, não por si mesmo, mas apenas através de determinações humanas pode deus, como mostrado, ser reconhecido. Aquilo o que vale à religião como deus ou absoluto é, então, não deus, mas o homem mesmo, concebido como uma outra essência ou como uma essência diferente dele. A religião não tem, por conseguinte, nenhum conteúdo aparte, próprio

\begin{tabular}{|l|l|l|l|l|}
\hline Qevista Dialectus & Ano 2 & n. 4 & Janeiro-Junho 2014 & p. 78-91 \\
\hline
\end{tabular}


ou particular; ela apenas transforma "inconsciente" as determinações do homem em um ser autônomo, divino; todavia, ela quer conscientemente anular esta identidade (Identität) e unidade (Einheit) da essência divina com a humana, pois ela acredita que deus é um ser inteiramente distinto da essência humana, porque ele, como "ser absoluto e infinito", contém uma abundância inesgotável de diferentes predicados, dos quais o homem conhece apenas uma parte. Este conceito teológico de deus é apenas uma representation sem realidade, na verdade, representação da sensibilidade, separada de todas as determinações do espaço e do tempo, através das quais um ser existente deve, primeiro, necessariamente ser localizado. Se os predicados divinos são determinações da sensibilidade humana, poder-se-ia disso deduzir que o sujeito (=deus) destes predicados é humano. Feuerbach nomeia duas determinações essenciais de tais predicados: uma é universal, metafísica, como a totalidade (Ganzheit), a infinitude (Unendlichkeit), a indeterminidade (Unbestimmtheit), e serve à religião como um princípio absoluto; a outra é particular, pessoal, como o amor (Liebe), a justiça (Gerechtigkeit), a virtude (Tugend), e caracteriza a essência da religião. Mas "a religião nada sabe de antropomorfismos: os antropomorfismos não são para ela antropomorfismos." (Ibidem, p. 63). Os predicados, os quais o homem faz a si de deus, são já a essência de deus, pois as representações de deus não são diferentes daquilo o que ele em si é. A teologia como reflexion da religião assevera, ao contrário, a distinção entre deus e o homem, asseveração essa que tem como desígnio, como visto, apagar da consciência a unidade ou a identidade inseparável entre eles; a separação de deus do homem vale para ela como oposição entre a criatura (Kreatur), o ser finito, considerado como nada, e o criador (Schöpfer), o ser infinito, representado como tudo, o todo.

A consideração acima mencionada, segundo a qual o homem é nada e, consequentemente, deus é tudo, evidencia claramente que a teologia cristã encerra em si mesma uma contemplação meramente negativa, hostil ao homem. Em síntese, ela torna o homem pobre, para enriquecer deus. Feuerbach afirma que ela, em contraposição ao materialismo e ao naturalismo, não possui nenhuma consciência do limite, por isso deus encontra-se para ela fora das fronteiras da sensibilidade, das barreiras da legalidade da natureza. Apenas deus, ou melhor, o ser puro é para ela o bem, pois o homem, na medida em que está submetido à necessidade, às carências corporais, está já corrompido e é inadequado ao bem. A teologia cristã não percebe, porém, que o ser bom, que ela diviniza e adora, é a própria essência boa do homem. O que ela declara sobre deus, isso deduz ela do homem. Disso resulta que o homem é o fundamento do deus cristão,

\begin{tabular}{|l|l|l|l|l|}
\hline Qevista Dialectus & Ano 2 & n. 4 & Janeiro-Junho 2014 & p. 78-91 \\
\hline
\end{tabular}


porque deus não é deus, se a ele o homem falta. Este pressuposto antropológico, a saber, que o homem é a verdadeira essência de deus e, destarte, o fundamento da religião cristã, não foi, contudo, reconhecido pela teologia cristã. A position desta reza assim:

\begin{abstract}
Deus não é o que o homem é, o homem não é o que deus é. Deus é o ser infinito, o homem, o finito; deus é perfeito, o homem imperfeito; deus é eterno, o homem transitório; deus é plenipotente, o homem impotente; deus é santo, o homem é pecador. Deus e o homem são extremos: deus é o unicamente positivo, o âmago de todas as realidades, o homem é o unicamente negativo, o cerne de todas as nulidades. (Ibidem, p. 75).
\end{abstract}

Feuerbach demonstra que esta discórdia principial entre deus e o homem, que a teologia afirma, é, na realidade, a oposição entre o homem e sua própria essência. Para ele, a segregação de deus do homem é nada mais do que uma obra da inteligência, do intelecto, pois deus per se, sem corpo, "sem carne e sangue", sem as necessidades e os impulsos sensíveis, é um puro abstractum, um puro res rationis, isto é, uma essência puramente pensada. A aceitação de um deus incorporal, impessoal, infinito corrobora, pois, apenas a infinitude do poder do pensamento. Deus é, então, a manifestação do pensar ou o pensar mesmo, que se transforma numa essência universal, infinita ou num êtré suprême, absoluto. Trata-se aqui não de duas essências ou substâncias, deus e o pensamento, mas apenas da unidade do pensar consigo mesmo, com sua própria essência, pois que deus é aquela representação (Vorstellung) ou ideia (Idee), que expressa a essência do entendimento humano contemplada como totalidade (Totalität) e perfeição (Vollkommenheit) de si mesma. Mas a essência do pensamento, idêntica com deus, colocada como uma essência sem antropomorfismo e afeto, não satisfaz à religião cristã, porque sua determinação distintiva para deus é a auto-afirmação da essência sensitiva, emocional, do homem. No âmbito da religião cristã, o homem deseja, pois, "que deus seja, mas precisamente porque ele quer que seu deus seja uma essência para ele, uma essência humana." (Ibidem, p. 90). Deus é para ela a perfeição moral, o ser absolutamente sagrado, por assim dizer a essência moral do homem, mas venerada como uma essência sobre-humana e sobrenatural; ela põe no lugar do deus visível, sensível, um invisível, não-sensível. Por meio dela, o homem é estranho à sua própria essência, já que ele experimenta-se nela não como um ser sensível-temporal, social, mas puro, atemporal e isolado.

Assim considerado, deus e todos os conteúdos transcendentes são apenas produtos fantásticos da vontade humana, projeções humanas. Deste ponto de vista, o homem acredita em um deus, que é nada mais do que expressão de sua própria essência

\begin{tabular}{|l|l|l|l|l|}
\hline Qevista Dialectus & Ano 2 & n. 4 & Janeiro-Junho 2014 & p. 78-91 \\
\hline
\end{tabular}


sensível, emotiva. ${ }^{3}$ Disso não segue, todavia, que o homem se reduza à sensibilidade pura, fora do espírito e do querer. Para Feuerbach, somente três essências universais - o amor (Liebe), o espírito (mens, Geist) e a vontade (volutas, Wille) - podem satisfazer inteiramente o homem, porque elas trazem em si a totalidade de suas determinações. Esta totalidade anuncia a religião cristã apenas indireta e invertidamente, na medida em que ela, como patenteado, faz inconscientemente das determinações humanas as qualidades universais, abstratas de deus. Para ela, deus está, na verdade, repleto de conteúdo, mas abstraído da vida real, pois "quanto mais vazia for a vida, tanto mais rico, mais concreto será o deus. O esvaziamento do mundo real e o enriquecimento da divindade é um único e mesmo ato." (Ibidem, p. 148). Porque a religião cristã vê em deus a satisfação das necessidades internas do homem, ela retira, então, a vida dos limites postos pela natureza e, com isto, reduz as satisfações reais do homem a uma satisfação puramente ilusória; ela se abstrai da natureza e se refere ao mundo e a tudo o que nele é apenas em sua aparência, não em sua essência, porque apenas deus constitui para ela a essência.

Essa ideia, que deriva da essência humana a essência de deus, tem Feuerbach desenvolvido não só em A Essência do Cristianismo, mas também em alguns pequenos escritos, como A Essência da Fé no sentido de Lutero (Das Wesen des Glaubens im Sinne Luthers), A Diferença entre a Divinização pagã e cristã do Homem (Der Unterchied der heidnischen und christlichen Menschenvergötterung), História da Filosofia Moderna (Geschichte der neueren Philosophie) e Princípios da Filosofia do Futuro (Grundsätze der Philosophie der Zukunft). Em A Essência do Cristianismo, Feuerbach, fiel ao seu objeto de estudo, tem abstraído da natureza, porque no Cristianismo deus "existe" sem a natureza; o Cristianismo mesmo ignora a natureza, ou seja, põe no cume um deus antinatural, que através de seu puro querer cria e governa o mundo. Este escrito de Feuerbach tem por objeto deus apenas como um ser moral, no

\footnotetext{
${ }^{3}$ Cf. para isso outrossim o escrito Preleções sobre a Essência da Religião (Vorlesungen über das Wesen der Religion) (1848), no qual Feuerbach afirma: "Na religião, o homem não satisfaz nenhum outro ser; ele satisfaz nela sua própria essência." Ou ainda: "Os deuses de um povo vão até onde seus sentidos também alcançam." (FEUERBACH, 1967, p. 88-89). Em A Essência do Cristianismo (Das Wesen des Christentums), ele escreve também: "Se as plantas tivessem olhos, gosto e juízo - cada planta iria escolher a sua flor como a mais bela, porque o seu gosto não iria além da sua capacidade essencial produtiva." (FEUERBACH, 1973). Esta posição crítica de Feuerbach à imagem de deus filia-se àquela posição do pré-socrático Xenófanes, para quem deus (théos) é também uma obra do homem. Nos Fragmentos 15 e 16 diz Xenófanes: "Os egípcios dizem que os deuses têm nariz chato e são negros, os trácios, que eles têm olhos verdes e cabelos ruivos." Ou mais preciso ainda: "Mas se mãos tivessem os bois, os cavalos e os leões pudessem com as mãos desenhar e criar obras como os homens, os cavalos semelhantes aos cavalos, os bois semelhantes aos bois, desenhariam as formas dos deuses e os corpos fariam tais quais eles próprios têm.” (XENOPHANES, 1968, p. 121).
}

\begin{tabular}{|l|l|l|l|l|}
\hline Qevista Dialectus & Ano 2 & n. 4 & Janeiro-Junho 2014 & p. 78-91 \\
\hline
\end{tabular}


qual a essência moral do homem se põe, nada mais do que, absolutamente, isto é, manifesta sua essência divinizada e objetivada espiritualmente. Por isto, para Feuerbach, a teologia cristã é, como visto, em seu fundamento e resultado final antropologia. O Cristianismo, que se abstrai da natureza, adora não o sol, a lua, as estrelas, o fogo, o ar, mas as forças (vontade, entendimento, consciência etc.) que fundamentam a essência humana como essência divina em contraste com a natureza, por isto Feuerbach não tem falado, em A Essência do Cristianismo, da natureza, mas meramente da essência do homem como objeto da religião, como princípio subjetivo ou como conteúdo verdadeiro da representação de deus. Mais tarde, nas Preleções sobre a Essência da Religião (Vorlesungen über das Wesen der Religion), o próprio Feuerbach confessa que o descuido do momento da natureza como objeto da religião e do sentimento de dependência (Abhängigkeitsgefühls) como base da religião representa na Essência do Cristianismo uma grande lacuna e tem dado, neste sentido, mal-entendidos a respeito de sua filosofia.

\section{A naturalização de Deus na Religião Natural Pagã}

A lacuna deixada em A Essência do Cristianismo tem Feuerbach suprimida só em 1846 com seu pequeno escrito A Essência da Religião. Como o próprio título sugere, este pequeno escrito diferencia-se fundamentalmente da Essência do Cristianismo, pois seu objeto não é apenas a essência da religião cristã para si sozinha, mas também a essência da religião em geral, da pré-cristã, como da religião natural pagã. Feuerbach tinha em A Essência do Cristianismo reconhecido a essência suprema (deus) como a essência divina, espiritual do homem; agora, ele esclarece em A Essência da Religião que o objeto primeiro da religião natural, a saber, o deus físico, considerado como o autor do mundo, como a causa da natureza (das estrelas, pedras, plantas, animais e homens), expressa nada mais do que a essência divinizada, personifica, da natureza. Se o núcleo da essência do Cristianismo reza que a teologia é antropologia (Anthropologie), assim o segredo da religião natural (da teologia física) é a fisiologia (Physiologie). A expressão "físiologia" ou "física" não deve ser aqui entendida no sentido estreito, atual; ela deve, pelo contrário, ser concebida no sentido antigo, universal de cosmologia. Feuerbach resume, por conseguinte, sua filosofia em duas palavras: homem (antropologia) e natureza (fisiologia). Porque o homem é um ser sensível, dependente, o fundamento de sua existência pressupõe uma outra essência fora

\begin{tabular}{|l|l|l|l|l|}
\hline Qevista Dialectus & Ano 2 & n. 4 & Janeiro-Junho 2014 & p. 78-91 \\
\hline
\end{tabular}


de si mesmo, isto é, fora e além de si mesmo. Esta essência, à qual ele deve o nascimento e a preservação de sua existência, chama Feuerbach não de deus, nem de espírito, mas simplesmente de natureza. Esta, considerada fisicamente, mas não moralmente, é frente ao homem a essência inconsciente, incriada, eterna e primeira, segundo o tempo, não segundo o valor. Aquele ser determinado, no qual a natureza atinge a consciência, torna-se inteligível e pessoal, que pertence à natureza, dela nasce e permanece ligado a ela, é e se chama homem. Assim, para Feuerbach, o ser humano é segundo o tempo o ser secundário, nascido, mas, segundo a importância, o valor, é o ser primeiro. Neste sentido, para se entender a filosofia de Feuerbach, pode-se dizer que sua pretensão consiste em negar o ser aparente, fantástico, da teologia, para afirmar, com isto, ao mesmo tempo a essência real do homem e da natureza.

De acordo com Feuerbach, a natureza é, como ela é realmente, ou seja, ela é factual, "impacial" e "fria", e ela faz o que ela faz, não intencionalmente, de propósito, não com saber e querer, mas necessariamente (tal qual a necessidade natural); isto é, porque ela é, é ela necessária, como ela é. Aqui, pode-se agora perguntar: como a natureza aparece ao homem, ou melhor, à percepção humana? Por um lado, a natureza não é nem divina, nem humana, não deduzida de um logos divino, nem de um espírito humano, pois ela se fundamenta sobre a base de sua legalidade na causalidade e reciprocidade, na necessidade e acidentalidade; mas assim, necessariamente, a priori, ela é compreensível em si mesma e não tem em si nenhum entendimento; mas, por outro lado, ela se funda, mediada pela linguagem, na aparência subjetiva das coisas, isto é, ela só pode ser compreendida na forma de analogias humanas, entendida pelo antropomorfismo. Esta concepção, segundo a qual a natureza existe, em princípio, em si e para si, independente do homem e que todas as aproximações acerca dela são apenas aparências humanas, conceitos subjetivos, ganhou nos escritos posteriores de Feuerbach significativo peso. Nesta situação paradoxal, Feuerbach tenta realizar uma correlação entre o homem e a natureza. Um elemento dessa relação é para ele não só a segurança (Geborgenheit), a unidade (Einheit), por assim dizer do homem como parte da natureza, mas também a distância (Distanz), o medo (Angst), a dependência (Abhängigkeit), que determina a relação do homem com a natureza. O homem não é, então, de modo nenhum, um ser sem necessidade, meramente espiritual; ele é, pelo contrário, também um ser corporal-sensível, físico, e, por isto, ele é dependente da natureza e precisa dela para o seu nascimento, desenvolvimento e autopreservação. A dependência do homem de um fato natural, que pode ameaçar a sua existência, faz da natureza para ele a causa

\begin{tabular}{|l|l|l|l|l|}
\hline Qevista Dialectus & Ano 2 & n. 4 & Janeiro-Junho 2014 & p. 78-91 \\
\hline
\end{tabular}




\section{A RELIGIÃO EM FEUERBACH: DEUS NÃO É DEUS...}

Eduardo F. Chagas

do medo e da insegurança, porque ele sabe que, sem ela, ele não pode ser. Feuerbach entende a natureza, no entanto, não como uma natureza sagrada, "misteriosa", tal como ela é objeto da religião natural (Naturreligion), isto é, como algo sobrenatural, mas apenas como um sistema de leis, como um passivo potencial, sobre o qual o homem também pode reagir e que pode ser usado por ele. Através de sua crítica à religião natural, Feuerbach chega à convicção que o poder da natureza pode ser quebrado e superado por meio da ciência e da cultura. O entusiasmo de Feuerbach pela ciência da natureza (Naturwissenschaft) e seu método, que ele já manifestara nas Teses Provisórias para a Reforma da Filosofia (Vorläufigen Thesen zur Reform der Philosophie) expressa-se também claramente nos textos de maturidade, nos quais ele tenta fundir uma nova relação da ciência com a filosofia. Nesse empreendimento, a ciência da natureza serve de base à filosofia, pois ela fornece uma contribuição para a superação tanto da especulação, que desenvolveu o homem só na pura auto-reflexão e deixou esquecida a natureza (isto é, a natureza concebida apenas algo posto pelo espírito, como seu outro na exterioridade), como também do tratamento teológico acerca do mundo, que deixa nascer, por meio de sua doutrina da creatio ex nihilo, uma abismo entre a causalidade efetiva, real, da natureza e causalidade fictícia de um deus criador (a natureza foi entendida aqui como um "grande mistério" da criação divina). Frente a isto, a ciência da natureza não conhece nenhuma influência sobrenatural sobre a natureza e/ou sobre-humana sobre o homem, mas apenas exemplos e fatos empíricos. Neste contexto, deve-se, todavia, chamar a atenção para o fato de que Feuerbach não era "um cientista espiritual" da natureza, pois, para ele, a ciência da natureza, em contraste com a filosofia, não dá acesso ao todo, à totalidade, e à essência do homem, porque ela está baseada em campos específicos (unilateralidade) e em questões especializadas (reducionismo). Embora Feuerbach confesse que o homem é um ser nascido da natureza e que a preservação de sua existência pressupõe a natureza, parece, para ele, sem sentido falar de uma ciência da natureza ou uma filosofia da natureza sem o homem, sem o qual não provinham seres do pensamento, da fantasia, como deus, liberdade etc. Para Feuerbach, a natureza é "não-humana", natureza externa, mas que existe para o homem, pois ela se torna explicável, reconhecível, na medida em que ela é apropriada pelo homem através de seu entendimento.

\section{Considerações Finais}

\begin{tabular}{|l|l|l|l|l|}
\hline Qexista Dialectus & Ano 2 & n. 4 & Janeiro-Junho 2014 & p. 78-91 \\
\hline
\end{tabular}




\section{A RELIGIÃO EM FEUERBACH: DEUS NÃO É DEUS...}

Eduardo F. Chagas

Enquanto em A Essência do Cristianismo a religião foi representada, como mostrado, como expressão da consciência humana, deus como projektion das qualidades sensíveis e espirituais do gênero humano e do homem como uma essência absoluta e infinita, que se eleva sobre a natureza, e precisamente por isto tratou-se apenas da essência do homem, ou seja, de um discurso antropomórfico da natureza, porque ela está submetida ao homem, agora, nos escritos A Essência da Religião (Das Wesen der Religion) (1846), Complementos e Esclarecimentos à Essência da Religião (Ergänzungen und Erläuterungen zum Wesen der Religon) (1846) e Preleções sobre a Essência da Religião (Vorlesungen über das Wesen der Religion) (1848), a natureza (Natur) é o objeto original da religião e o fundamento de todas as coisas. O ser, "que o homem pressupõe, com o qual ele se relaciona necessariamente, sem o qual nem sua existência, nem sua essência podem ser pensadas, este ser, meus senhores", diz Feuerbach, "não é outra coisa do que a natureza, não vosso deus." (FEUERBACH, 1967, p. 27). Se a reflexão de Feuerbach sobre a religião em A Essência do Cristianismo reduzia-se meramente ao ponto de vista subjetivo do sentimento, já que a divindade fora atribuída ao homem, agora rejeita Feuerbach a religião apenas parcialmente, pois ela contém, de acordo com sua concepção, uma relação necessária para a natureza. Correspondendo a isto, ele diz, por exemplo em A Essência da Religião, que é sua tarefa "defender, justificar, fundamentar" a religião natural "contra as explicações e deduções teísticas da natureza.” (Ibidem, p. 99). Neste contexto, deve ser, no entanto, ressaltado que não se trata para Feuerbach da religião natural (Naturreligon) em si, que, segundo ele, corresponde, e é para superar, à consciência infantil, pré-consciente, précientífica. Pelo contrário, Feuerbach se interessa pela religião natural, porque ela contém uma indicação decisiva para o significado constitutivo da natureza e testemunha, ao mesmo tempo, a essência objetiva do sentimento de dependência (Gefühl der Abhängigkeit) do homem pela natureza. A religião natural demonstra, por conseguinte, a relação do homem com a natureza; ela representa a verdade da sensibilidade, que prova que a natureza é a essência que abrange o homem, que o homem é uno com ela: nela vive, se desenvolve e morre. Assim entendido, a religião natural constitui para Feuerbach uma chave para o entendimento do homem.

Apesar desta avaliação parcialmente positiva da religião da natureza, chega Feuerbach, no entanto, à conclusão de que ela não concebe, no fundo, a natureza real, objetiva; pelo contrário, reflete-se também nela apenas a "verdade do homem", pois o homem religioso-natural vê nela não a natureza, como ela é realmente, mas a percebe

\begin{tabular}{|l|l|l|l|l|}
\hline Qevista Dialectus & Ano 2 & n. 4 & Janeiro-Junho 2014 & p. 78-91 \\
\hline
\end{tabular}


tão-somente como objeto de sua fé, de sua veneração religiosa ou de sua imaginação. Porque a natureza oferece ao homem o que ele precisa, foi ela idolatrada como divina; a veneração (Verehrung) ou divinização (Vergötterung) da natureza significa, por conseguinte, a sua "antropomorfização", isto é, a sua "humanização" pela religião, pois o valor, que o homem põe na natureza, é apenas o valor que ele atribui a si mesmo, à sua própria vida. A religião da natureza tem, na verdade, por finalidade transformar a essência não-sagrada, não-humana, da natureza numa essência "sagrada", "personificada". Mas, assim como o panteísmo, Feuerbach a critica, precisamente porque ela faz, através dessa transformation, da natureza um deus.

Em oposição a isso, ele não vê a natureza como algo sagrado, divino, isto é, como objeto religioso, tal como ela aparece na religião da natureza, mas, pelo contrário, como uma essência objetiva que existe apenas por si mesma, independentemente do homem. Como justificativa para este seu procedimento, pelo qual ele quer livrar a natureza de todas as considerações religiosas e antropológicas, vale a ele que a natureza é o ente que produz tudo de si e por si e, por conseguinte, não deve ser vista como aquilo o que ela não é, isto é, 1. nem como divina (em forma do teísmo), 2. nem como humana (em forma do Idealismo). A natureza, para ele, sempre existiu, quer dizer, ela existe por si e tem seu sentido apenas em si mesma; ela é ela mesma, ou seja, nenhuma essência mística, pois por detrás dela não se oculta, nem se esconde nada humano, nada divino, nenhum absolutum transcendental ou ideal. O conceito de natureza designa tudo o que se mostra sensivelmente ao homem como fundamento e essência de sua vida; trata-se, pois, primeiro daquela essência (luz, ar, água, fogo, plantas, animais etc.), sem a qual o homem não pode nem ser pensado nem existir. A natureza é, assim, a pluralidade de todas as coisas e seres sensíveis que realmente são. Embora haja neste ponto uma certa concordância entre Feuerbach e Schelling, distancia-se, porém, Feuerbach de Schelling, pois para Feuerbach a natureza é em si e por si, mas não para si; ela é necessária e regida por leis próprias, sem espírito e sem sujeito, isto é, o independente de toda essência humana ou divina, o indeduzível, o que consiste por si mesmo, por assim dizer a essência originária, primeira e última.

Assim sendo, pode-se dizer que 1. por um lado, a natureza existe per se (em si e por si) e age, em princípio, sem intencionalidade (Absicht), sem querer (Willen) ou saber (Wissen); ela tem seu "entendimento" apenas no entendimento do homem e prova sua essencialidade mediante qualidades, conexões e relações materiais; 2. mas, por outro lado, para fazê-la a nós inteligível, é-nos inevitável que devamos empregar sobre ela

\begin{tabular}{|l|l|l|l|l|}
\hline Qevista Dialectus & Ano 2 & n. 4 & Janeiro-Junho 2014 & p. 78-91 \\
\hline
\end{tabular}


analogias, expressões ou conceitos, como ordem, finalidade, sabedoria etc.. Aquilo que o homem acredita reconhecer na natureza como "entendimento", "espírito", que empresta a ela uma "teleologia", é, portanto, apenas uma representação humana. Assim, no que tange a todas as aproximações à natureza trata-se para Feuerbach, meramente, de conceitos antropológicos, subjetivos, pois, na natureza, tudo acontece sob o fundamento da necessidade e há nela apenas forças, elementos e seres naturais, isto é, leis naturais, às quais a existência humana está submetida. Partindo da necessidade e das leis da natureza, Feuerbach exclui dela todos os critérios humanos ou "efeitos de deus" para a sua valorização e postula, com isto, a sua autonomia. Precisamente este postulado de Feuerbach em relação ao status da natureza oferece, na situação presente, pontos de referências para uma resistência contra toda exploração arbitrária e brutal da natureza a favor dos desígnios e desejos ilimitados do homem e, ao mesmo tempo, fornece, consequentemente, sugestões e contribuições para um debate frutífero sobre a crise ecológica atual.

\section{Referências Bibliográficas}

CHAGAS, Eduardo F.; REDYSON, Deyve (Orgs.). Ludwig Feuerbach: Filosofia, Religião e Natureza. São Leopoldo: Editora Nova Harmonia, 2011.

A Majestade da Natureza em Ludwig Feuerbach. In: ; REDYSON, Deyve; PAULA, Marcio G. de. Homem e Natureza em Ludwig Feuerbach. Série Filosofia, n ${ }^{\circ}$. Fortaleza: Edições UFC, p. $37-$ $65,2009$.

A Aversão do Cristianismo à Natureza em Feuerbach. In: Philósophos - Revista de Filosofia, Goiânia, v. 15, n. 2, p. 52-82, 2010.

FEUERBACH, L. Zur Beurteilung der Schrift "Das Wesen des Christentums". Org. por W. Schuffenhauer, GW 9, Berlin: Akademie-Verlag, 1970.

Vorlesungen über das Wesen der Religion. Org. por W. Schuffenhauer, GW 6, Berlin: Akademie-Verlag, 1967.

Das Wesen des Christentums. Org. por W. Schuffenhauer, GW 5, Berlim: Akademie-Verlag, 1973.

Para a Crítica da Filosofia de Hegel. Edição Bilíngue. Tradução: Adriana Veríssimo Serrão. Apresentação: Eduardo Chagas e Deyve Redyson. São Paulo: LiberArs, 2012.

\begin{tabular}{|l|l|l|l|l|}
\hline Qevista Dialectus & Ano 2 & n. 4 & Janeiro-Junho 2014 & p. 78-91 \\
\hline
\end{tabular}


RAWIDOWICZ, S. Ludwig Feuerbachs Philosophie - Ursprung und Schicksal. Berlin: Walter de Gruyter \& Co, 1964.

XENOPHANES. Fragmente - Vorsokratiker. Org. por W. Capelle, Stuttgart: Reclam, 1968. 